\title{
Cross-Linked Hyaluronic acid can Prevent the Capsular Contracture Formation
}

\author{
Ting-Mao Chou ${ }^{1 \#}$, Chin-Hao Hsu ${ }^{2 \#}$, Tai-I Hsu ${ }^{3 \#}$, Leo Shaw ${ }^{4}$, Wen-Ching Wang ${ }^{5}$, Chao-Ming Hung ${ }^{6}$, I-Ming Jou ${ }^{2^{*}}$ and Yao-Lung Kuo ${ }^{*}$
}

1Departmet of Plastic surgery, E-Da Hospital, Kaohsiung, Taiwan

2Department of Plastic Surgery, Ditmanson Medical Foundation Chia-Yi Christian Hospital, Taiwan

3Department of Orthopedics, E-Da Hospital, Taiwan

4Department of Orthopedics, National Cheng Kung University Hospital, Taiwan

5Department of Orthopedics, Chi Mei Medical Center, Taiwan

6Department of General Surgery, E-Da Hospital, Taiwan

7Department of Surgery, National Cheng Kung University Hospital, Taiwan

\#These authors contributed equally to this work.

"Corresponding authors: I-Ming Jou, Department of Orthopaedics, E-DA Hospital, I-Shou University, Kaohsiung, Taiwan. Tel: 886-7-615-0011; Email: ed109325@edah.org.tw

Yao-Lung Kuo, Department of Plastic Surgery, National Cheng Kung University Hospital, College of Medicine, National Cheng Kung University, Tainan, Taiwan. Tel: 886-6-235-3535; Fax: 886-6-276-6676; E-mail: ylkuo@mail.ncku.edu.tw

Rec date: November 14, 2017; Acc date: December 12, 2017; Pub date: December 15, 2017

Copyright: ( 2017 Chou TM, et al. This is an open-access article distributed under the terms of the Creative Commons Attribution License, which permits unrestricted use, distribution, and reproduction in any medium, provided the original author and source are credited.

\begin{abstract}
Introduction: Breast reconstruction using silicone implants is a widespread choice, however, breast capsular contracture $(B C C)$, a response of the immune system to foreign materials, is the most affliction and frustration fibrosis complications after silicone implantation. Chronic inflammation-associated fibrosis is regarded as a main cause of BCC. Hyaluronic acid (HA) is an effective anti-adhesive and anti-fibrotic agent. Furthermore, 1,4-butanediol diglycidyl ether-cross-linked hyaluronan hydrogel ( $\mathrm{cHA}$ ) is a non-resorbable cross-linked hyaluronan-derived polymer with no cytotoxicity and high stability. This study aims to evaluate the potential of $\mathrm{cHA}$ on preventing BCC in breast surgery using silicone implants.
\end{abstract}

Methods: The effect of $\mathrm{CHA}$ on BCC will be examined in breast BCC rat model.

Results: Our study showed that $\mathrm{cHA}$ decreased fibrosis-regulated factors transforming growth factor beta 1 (TGF- $\beta 1$ ) and tissue inhibitor of metalloproteinase (TIMP) expressions and increased metalloproteinase (MMP) MMP-9 expression in capsule tissue. cHA significantly decreased inflammatory mediators tumor necrosis factoralpha (TNF- $\alpha$ ), interleukin IL-6, nitric oxide (NO), as well as inducible nitric oxide synthase (iNOS) expressions. In addition, cHA significantly decreased transcription factor nuclear factor kappa B (NF-kB) activation in silicone surrounded tissue.

Conclusions: $\mathrm{cHA}$ showed prevention in BCC formation through inhibiting NF-KB -associated inflammation in rats with silicone implantation.

Keywords: Cross-linked hyaluronan hydrogel; Breast augmentation; Capsular contracture; Fibrosis; Nuclear factor kappa B

\section{Introduction}

Breast augmentation Silicone implants have been used extensively for breast reconstruction following mastectomy since 1964. However, silicone implants combined with autologous proteins trigger a specific local immune response which leads to fibrosis promoted by the production of profibrotic cytokines. The chronic inflammation and fibrosis leads to development of breast capsular contracture (BCC) [1]. $\mathrm{BBC}$ causes breast firmness, uncomfortableness, pain, a change in the appearance of the breast, and palpability of the silicone implants. In clinical settings, the incidence of symptomatic BCC ranges from 5 to $20 \%[2,3]$ and additional surgeries may be required to clean the scar tissue which may involve removal or replacement of the implants [4]. Currently, there is no effective treatment to avoid BCC.

Chronic inflammation and fibrosis participate in the development of capsular contracture. BCC is result Hyaluronic acid (HA) is an effective anti-adhesive and anti-fibrotic agent used to inhibit peripheral nerve adhesion, scar formation, and post-laminectomy fibrosis formation [5-9]. To improve the mechanical properties and lengthen the residence time, the polymer chains of HA are cross-linked with linker molecules, such as divinyl sulfone, homobifunctional glycidyl ethers, glutaraldehyde, and formaldehyde 1,4-butanediol diglycidyl ether-cross-linked hyaluronan hydrogel (cHA) is a non-resorbable cross-linked hyaluronan-derived polymer with no cytotoxicity and adverse changes in electrophysiology and neuro behavior [10]. Therefore, topical treatment of $\mathrm{cHA}$ on implant material may be effective in preventing BCC; however, the effect of cHA on BCC- 
associated fibrosis and inflammation has never been investigated. The aim of the present study is to evaluate the potential of cHA on BCC prevention after silicone implantation in rats.

\section{Materials and Methods}

\begin{abstract}
Animals
Female SPF Wistar rats weighing 200-300 g were obtained from our institution's Laboratory Animal Center. They were individually housed in a room with a 12-hour dark/light cycle and central air conditioning $\left(25^{\circ} \mathrm{C}, 70 \%\right.$ humidity), allowed free access to tap water, and fed a rodent diet from Richmond Standard, PMI Feeds, Inc (St Louis, MO), with or without a sesame oil supplement. The animal care and experimental protocols were in accordance with nationally approved guidelines. (IRB No: B-ER-102-262)
\end{abstract}

\section{Inducing capsule contracture in rats}

The rats were anesthesia with Zoletil $(1 \mathrm{ml}$. Zoletil with concentration of $10 \mathrm{mg} / \mathrm{ml}$ combined with Rompun $0.1 \mathrm{ml}$. for intraperitoneal injection, the dosage: $0.05-0.06 \mathrm{ml} / 10 \mathrm{gm}$ ) to sedation for the surgery. Before surgery, the dorsum of 20 anesthetized rats ( $\mathrm{n}=10$ for each group) were shaved and cleansed with povidone iodine, and all surgical procedures were carried out under sterile conditions. Two $1-\mathrm{cm}$ skin incisions were made on the back of each animal at a distance sufficient to avoid merging of the pockets. Pockets were created by blunt dissection beneath the panniculus carouses plane with dimensions barely sufficient to accommodate the implant. One silicone implant (The MENTOR ${ }^{\circ}$ ARTOURA $^{\mathrm{m}}$ Breast Tissue Expander, cut the expander into size: $1 \times 2 \mathrm{~cm}^{2}$ ) covered with HA with $100 \mu \mathrm{l}$ (HA group, $0.5 \%$ BDDE-cross-linked HA Maxigen Biotech Inc.) was placed in left pocket while another one without HA was placed in right pocket $(\mathrm{C}$ group). Incisions were then closed with stitches making sure the suture line was not directly over the implant. The rats were kept and observed the behavior to evaluate the wound condition; if the animals showed the weight loss over than $10 \%$, reduced mobility, poor appetite, weakness and self-mutilation, the animal were intraperitoneal injected with the Butorphanol 0.1-0.5 mg/100 g. At the sacrificed time point, the rats were anesthetized with Barbiturate $(100 \mathrm{mg} / \mathrm{kg})$ intraperitoneal injection to over dose sedation. The silicone implants were removed together with their capsules 4 months after implantation.

\section{Immunohistochemistry staining (IHC)}

The collected samples were fixed with $4 \%$ formaldehyde. It should be the samples were dehydrated and embedded in the paraffin for the slice into the slide to examine the protein expression with the immunohistochemistry staining (Figure 1). The slides sections were immersed within xylene, and rehydrated in alcohol gradient and then rinsed in phosphate buffer for primary antibody detection. The samples were incubated with Anti-TGF- $\beta 1$ primary antibody for 12 hours at $4^{\circ} \mathrm{C}$ after being blocked with $3 \%$ hydrogen peroxide, avidin and biotin for 15 minutes each. The slides were then incubated with a biotinylated secondary antibody for 1 hour, following by a 15-minutesincubation with streptavidin peroxidase, 1-minute-hematoxylin-stain. And then, the slides were dehydrated by graded ethanol, dehydrated by xylene, and mounted with rhamsan gum. The results were observed under optical microscope and photographed.

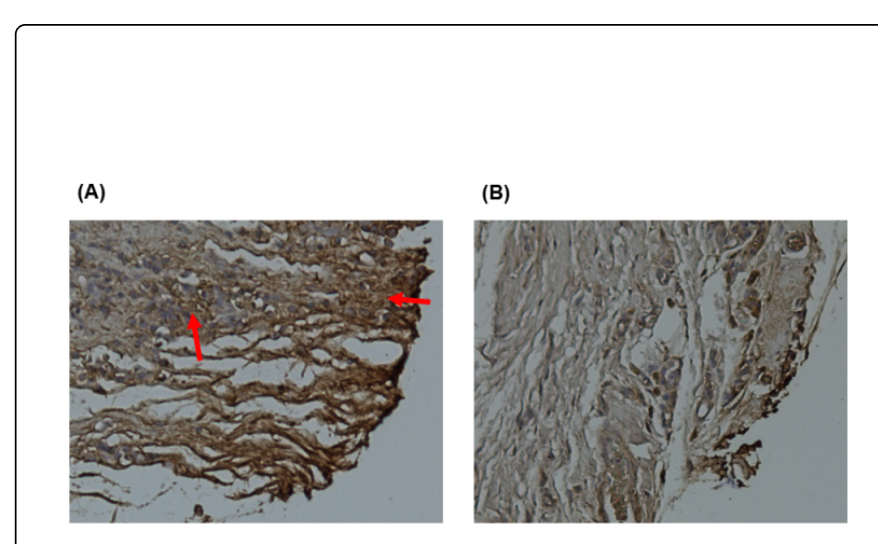

Figure 1: Immunohistochemistry study of TGF- $\beta 1$ expression in capsule tissue. Immunohistochemistry staining for TGF- $\beta 1$ protein expression (brown color; arrows) in capsule tissue from non-HA group (C group) (A) and cHA-treated groups (HA group) (B) (X100).

\section{Western blotting}

Nuclear extraction kit (Sigma, Inc., St. Louis, MO) was used to separate nuclear and cytosolic protein. Fifty micrograms of protein was loaded on SDS-PAGE, and then transferred to nitrocellulose sheets (NEN Life Science Products, Inc., Boston, MA). After blocking, the blots were incubated with TGF- $\beta 1$, matrix metalloproteinases (MMP)-2, MMP-9, inducible nitric oxide synthase (iNOS), nuclear factor-kappa B NF- $\kappa$ B, or $\beta$-actin antibody (dilution 1:1000) in $5 \%$ non-fat skim milk (using $\beta$-actin as a loading control). After washing, the blots were incubated with secondary antibodies conjugated with alkaline phosphatase (dilution 1:3000) (Jackson ImmunoResearch Laboratories, Inc., Philadelphia, PA). Immunoblots were developed using bromochloroindolyl phosphate/nitroblue tetrazolium solution (Kirkegaard and Perry Laboratories, Inc., Baltimore, MD).

\section{Measuring tumor necrosis factor TNF- $\alpha$ and interleukin (IL)-6 in tissue}

Cytokines including TNF- $\alpha$ and IL-6 levels were quantitatively measured by using ELISA kits (Duo-Set; R\&D Systems Inc., Minneapolis, MN) followed the manufactory protocol. The protein concentration in tissue homogenate was determined by using protein assay dye (Bio-Rad Laboratories, Hercules, CA, USA).

\section{Assessing Nitric oxide (NO) concentration in tissue}

Briefly, the amounts of nitrite in serum were measured following the Griess reaction by incubating $100 \mathrm{ml}$ of sample with $100 \mathrm{ml}$ of Griess solution at room temperature for $20 \mathrm{~min}$. The absorbance was measured at $550 \mathrm{~nm}$ by a spectrophotometer. Nitrite concentration was calculated by comparison with a standard solution of known sodium nitrite concentrations. 
Page 3 of 5

\section{Statistical analysis}

Data were expressed as the means \pm standard deviation (SD). The data were used Wilcoxon signed rank test and paired student $t$ test to make pairwise comparisons between 2 groups. Statistical significance was set at $\mathrm{p}<0.05$. The number for each group was 10 animals.

\section{Results}

\section{The effect of cHA on fibrosis}

To investigate the effect of HA on fibrosis regulation of capsule formation during silicone implantation, TGF- $\beta 1$, MMP-9, and TIMP expressions were detected. In immunohistological results, TGF- $\beta 1$ protein (brown color; arrows) expressed more in non-HA group (C group) than HA-treated groups (HA group). Western blotting results show that capsular active TGF- $\beta 1$ expressions were $5.3 \pm 0.03$ relative units in $\mathrm{C}$ group and $1.10 \pm 0.04$ relative units in HA group (p value $<0.0001)$. Non-activated TGF- $\beta 1$ expressions were $4.29 \pm 0.54$ relative units in $\mathrm{C}$ group and $0.98 \pm 0.13$ relative units in HA group (p value $<0.0001)$. Capsular expressions of MMP-9 were $0.47 \pm 0.19$ relative units in $\mathrm{C}$ group and $1.43 \pm 0.36$ relative units in HA group (p value $<0.0001$ ). Capsular expressions of TIMP were $6.09 \pm 2.81$ relative units in $\mathrm{C}$ group and $0.82 \pm 0.13$ relative units in HA group (p value $=0.0023$ ). These differences also reached statistical significances (Figure 2).
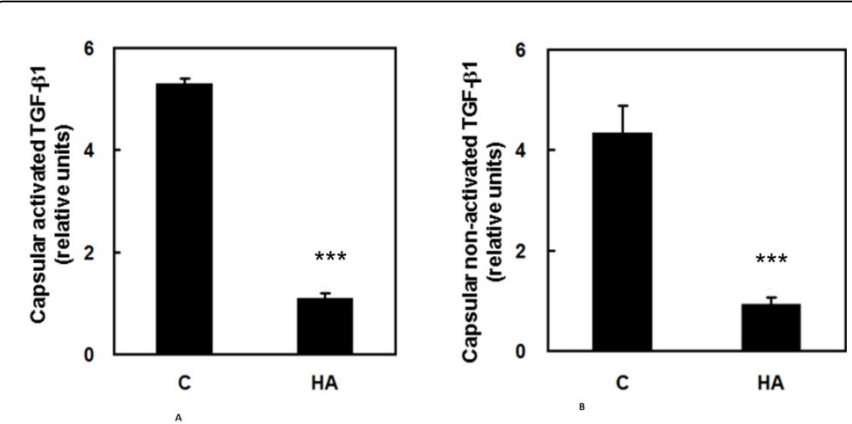

Figure 2: Effects of cHA on activated and non-activated TGF- $\beta 1$ expressions in capsule tissue. Western blot was used to assess the changes of activated (A) and non-activated (B) TGF- $\beta 1$ expressions in the capsule tissue from non-HA group ( $\mathrm{C}$ group) and cHAtreated groups (HA group). Data were means \pm standard deviation (SD) $(\mathrm{n}=10) .{ }^{* * *} \mathrm{P}<0.001$ compared with $\mathrm{C}$ group.

\section{The effect of cHA on inflammation}

To investigate the role of inflammatory control on HA-associated protection, inflammatory mediators TNF- $\alpha$, IL-6, NO, as well as iNOS expressions were detected in capsule tissue. ELISA results show that capsular TNF- $\alpha$ levels were $387 \pm 57 \mathrm{pg} / \mathrm{mg}$ protein in C group and 289 $\pm 29 \mathrm{pg} / \mathrm{mg}$ protein in HA group (p value $=0.018$ ). Capsular IL-6 levels were $2040 \pm 52 \mathrm{pg} / \mathrm{mg}$ protein in $\mathrm{C}$ group and $1654 \pm 169 \mathrm{pg} / \mathrm{mg}$ protein in HA group ( $\mathrm{p}$ value $<0.0001$ ). Griess assay results show that capsular nitrite levels were $21.3 \pm 4.1 \mathrm{mmol} / \mathrm{mg}$ protein in $\mathrm{C}$ group and $10.2 \pm 5.9 \mathrm{mmol} / \mathrm{mg}$ protein in HA group ( $\mathrm{p}$ value $=0.0002$ ). Western blotting results show that capsular iNOS expressions were $5.5 \pm 4.2$ relative units in $\mathrm{C}$ group and $1.5 \pm 0.8$ relative units in HA group(p value $=0.0096$ ). These differences also reached statistical significances.

\section{The effect of cHA on NF- $\mathrm{KB}$ activation}

To investigate the role of NF- $\kappa \mathrm{B}$ control on HA-associated antiinflammation, the NF- $\kappa \mathrm{B}$ activation was detected in capsule tissue. Western blotting results show that capsular nuclear NF- $\mathrm{kB}$ expressions were $0.94 \pm 0.03$ relative units in $C$ group and $0.76 \pm 0.13$ relative units in HA group ( $\mathrm{p}$ value $=0.0337$ ). The difference reached statistical significances.

\section{Discussion}

In this study, we have demonstrated the protective effect of cHA on BCC. cHA decreased fibrosis-regulated factors TGF- $\beta 1$ and TIMP expressions and increased MMP-9 expression in capsule tissue. cHA also significantly decreased inflammatory mediators TNF- $a$, IL-6, NO, as well as iNOS expressions. In addition, cHA significantly decreased transcription factor NF- $\kappa \mathrm{B}$ activation in silicone surrounded tissue. It is suggested that CHA may prevent BCC formation through inhibiting NF- $\kappa B$-associated inflammation in rsats with silicone implant insertion.

Injectable fillers, such as autologous fat graft or HA, might offer women the advantage of deciding their desired size in breast enhancement. The infection rate of $0.08 \%$ in the large scale study was lower than prosthesis implants [11]. However, due to the concern of degradation of the volume, prosthesis implantation is still the main procedure of breast augmentation. Immune response of foreign objects to the human body might cause capsular contracture and distort the aesthetics of the breast. The cause of capsular contracture might be bacterial infection, implant shell rupture, and hematoma, but nevertheless interaction between implant and the surrounding injured tissue. Implant surface modification of biomaterials to reduce the capsular thickness is proved, which may be due to down regulation of macrophage adhesion and activation [12]. However, possible mechanism is still unknown.

Inhibiting fibrosis is crucial in preventing BCC after silicone implantation. Severe fibrotic reaction to foreign body such as silicone implant is an important cause of capsular contracture [13]. In addition, the stage of capsular fibrosis after breast augmentation is one of the main indicators of the severity of BCC [14]. TGF- $\beta$ is a multifunctional cytokine that play a central role in tissue repair and fibrosis, which stimulates the production of various extracellular matrix proteins and inhibits the degradation of these matrix proteins [15]. TGF- $\beta 1$ has been regarded as the dominant factor causing capsular contracture [16]. The balance between MMP and TIMP is also important in regulation of fibrosis [17] MMP plays an anti-fibrotic role through cleavage of the ECM [18]. TIMP is an inhibitor of metallo proteinases. TGF- $\beta$ may also affect the balance through inhibiting MMP-9 expression [19] and increasing TIMP-1 expression [20]. The decrease in MMP-to-TIMP expression in capsular tissue of patients with silicone gel implants was observed with higher rates of capsular contracture [21]. In the present study, cHA decreased TGF- $\beta$ and TIMP expressions and increased MMP-9 expression in capsule tissue. It is suggested that cHA may prevent BCC through inhibiting fibrosis in silicone surrounded tissue.

Inhibiting inflammation may be involved in the anti-fibrotic effect of cHA after silicone implantation. Inflammation is commonly involved in the pathogenesis of fibrosis in many diseases. During inflammation, fibroblasts and myofibroblasts activation, and macrophage infiltration has been implicated in the production of ECM and inflammation-induced organ fibrosis $[22,23]$. TGF- $\beta$ produced or 
released by infiltrating cells during inflammation plays an important role in activation of fibroblast [15]. Pro-inflammatory mediators including TNF- $a$, IL-6, and NO are important indicator of inflammation. In addition, these pro-inflammatory mediators are important in the activation of inflammation-related cells and in the pathogenesis of fibrosis $[24,25]$. In the present study, cHA treatment decreased TNF- $\alpha$, IL- 6 , NO, as well as iNOS expressions in silicone surrounded tissue. It is likely that cHA may inhibit fibrosis via inhibiting pro-inflammatory mediators' production in silicone surrounded tissue.

NF- $\kappa B$ may play an important role in pro-inflammatory mediator's production in BCC. NF- $\mathrm{KB}$ is the dominant transcription factor on producing pro-inflammatory mediators [26] Inhibition of NF- $\kappa \mathrm{B}$ activation decreased TNF- $\alpha$, IL-6, and iNOS expressions during inflammatory stimulus [27-29]. In the present study, cHA significantly decreased nuclear NF- $\kappa \mathrm{B}$ expression in silicone surrounded tissue. Therefore, cHA may decrease TNF- $\alpha$, IL- 6 , and NO production by inhibiting NF- $\mathrm{\kappa B}$ pathway activation. We concluded that $\mathrm{cHA}$ is able to prevent $\mathrm{BCC}$ fibrosis through inhibiting transcription factor NF- $\mathrm{kB}$ activation in rats. CHA has the potential in preventing BCC from patients with silicon implanted surgery. However, more investigation will be needed to confirm this.

\section{Acknowledgments}

This work is supported by grant (104-2622-E-006-021-CC2) from Ministry of Science and Technology, R.O.C., Taiwan and National Cheng Kung University Hospital NCKUH-10306017, NCKUH-10407020, NCKUH-20160041, Ministry of Science and Technology 104-2622-E-006-021-CC2.

\section{Conflict of Interest}

None

\section{Financial source}

National Cheng Kung University Hospital NCKUH-10306017, NCKUH-10407020, NCKUH-20160041, Ministry of Science and Technology 104-2622-E-006-021-CC2. Research performed at Department of Orthopedics, National Cheng Kung University Hospital, and Tainan, Taiwan.

\section{References}

1. Brody GS (1997) On the safety of breast implants. Plast Reconstr Surg 100: 1314-1321.

2. Sevin A, Sevin K, Senen D, Deren O, Adanali G, et al. (2006) Augmentation mammaplasty: Retrospective analysis of 210 cases. Aesthetic Plast Surg 30: 651-654.

3. Spear SL, Murphy DK, Slicton A, Walker PS (2007) Inamed Silicone Breast Implant USSG. Inamed silicone breast implant core study results at 6 years. Plast Reconstr Surg 120 7: 8S-16S.

4. Prantl L, Poppl N, Horvat N, Heine N, Eisenmann-Klein M (2005) Serologic and histologic findings in patients with capsular contracture after breast augmentation with smooth silicone gel implants: Is serum hyaluronan a potential predictor? Aesthetic Plast Surg 29: 510-508.

5. Akeson WH, Massie JB, Huang B, Giurea A, Sah R, et al. (2005) Topical high-molecular-weight hyaluronan and a roofing barrier sheet equally inhibit postlaminectomy fibrosis. Spine J 5: 180-90.
6. Massie JB, Schimizzi AL, Huang B, Kim CW, Garfin SR,et al. (2005) Topical high molecular weight hyaluronan reduces radicular pain post laminectomy in a rat model. Spine J 5: 494-502.

7. Schimizzi AL, Massie JB, Murphy M, Perry A, Kim CW, et al. (2006) High-molecular-weight hyaluronan inhibits macrophage proliferation and cytokine release in the early wound of a preclinical postlaminectomy rat model. The spine journal: Official journal of the North American Spine Society 6: 550-556.

8. Asch HL, Lewis PJ, Moreland DB, Egnatchik JG, Yu YJ, et al. (2002) Prospective multiple outcomes study of outpatient lumbar microdiscectomy: should 75 to $80 \%$ success rates be the norm? J Neurosurg 96: 34-44.

9. Atlas SJ, Keller RB, Chang Y, Deyo RA, Singer DE (2001) Surgical and nonsurgical management of sciatica secondary to a lumbar disc herniation: Five-year outcomes from the Maine Lumbar Spine Study. Spine. 26: 1179-1187.

10. Lan SM, Jou IM, Wu PT, Wu CY, Chen SC (2015) Investigation into the safety of perineural application of 1,4-butanediol diglycidyl ethercrosslinked hyaluronan in a rat model. J Biomed Mater Res B Appl Biomater. 103: 718-726.

11. Ishii H, Sakata K (2014) Complications and management of breast enhancement using hyaluronic acid. Plast Surg (Oakv) 22: 171-174.

12. Hsieh CYC, Hu FW, Chen WS, Tsai WB (2014) Reducing the foreign body reaction by surface modification with collagen/hyaluronic acid multilayered films. ISRN biomaterials 2014: 8 .

13. Headon H, Kasem A, Mokbel K (2015) Capsular contracture after Breast Augmentation: An Update for Clinical Practice. Arch Plast Surg 42: 532-543.

14. Berry MG, Cucchiara V, Davies DM (2010) Breast augmentation: Part IIAdverse capsular contracture. J Plast Reconstr Aesthet Surg 63: 2098-2107.

15. Branton MH, Kopp JB (1999) TGF-beta and fibrosis. Microbes Infect 1:1349-1365.

16. Katzel EB, Koltz PF, Tierney R, Williams JP, Awad HA, et al. (2010) A novel animal model for studying silicone gel-related capsular contracture. Plast Reconstr Surg 126:1483-1491.

17. Becher N, Hein M, Uldbjerg N, Danielsen CC (2008) Balance between matrix metalloproteinases (MMP) and tissue inhibitors of metalloproteinases (TIMP) in the cervical mucus plug estimated by determination of free non-complexed TIMP. Reprod Biol Endocrinol 6: 45.

18. Han YP (2006) Matrix metalloproteinases, the pros and cons, in liver fibrosis. J Gastroenterol Hepatol 21 Suppl 3: S88-91.

19. Vaday GG, Schor H, Rahat MA, Lahat N, Lider O (2001) Transforming growth factor-beta suppresses tumor necrosis factor alpha-induced matrix metalloproteinase-9 expression in monocytes. J Leukoc Biol 69: 613-621.

20. Seeland U, Haeuseler C, Hinrichs R, Rosenkranz S, Pfitzner T, et al. (2002) Myocardial fibrosis in transforming growth factor-beta(1) (TGFbeta(1)) transgenic mice is associated with inhibition of interstitial collagenase. Eur J Clin Invest 32: 295-303.

21. Ulrich D, Ulrich F, Pallua N, Eisenmann-Klein M (2009) Effect of tissue inhibitors of metalloproteinases and matrix metalloproteinases on capsular formation around smooth and textured silicone gel implants. Aesthetic Plast Surg 33: 555-562.

22. Wynn TA, Barron L (2010) Macrophages: Master regulators of inflammation and fibrosis. Semin Liver Dis 30: 245-257.

23. Ueha S, Shand FH, Matsushima K (2012) Cellular and molecular mechanisms of chronic inflammation-associated organ fibrosis. Front Immunol 3: 71.

24. Leung TM, Fung ML, Liong EC, Lau TY, Nanji AA, et al. (2011) Role of nitric oxide in the regulation of fibrogenic factors in experimental liver fibrosis in mice. Histol Histopathol. 26: 201-211. 
Citation: Chou TM, Hsu TI, Hsu CH, Shaw L, Wang EC, et al. (2017) Cross-Linked Hyaluronic acid can Prevent the Capsular Contracture Formation. Gen Med (Los Angeles) 5: 305. doi:10.4172/2327-5146.1000305

Page 5 of 5

25. Fielding CA, Jones GW, McLoughlin RM, McLeod L, Hammond VJ, et al (2014) Interleukin-6 signaling drives fibrosis in unresolved inflammation. Immunity 40: 40-50.

26. Chu PY, Chien SP, Hsu DZ, Liu MY (2010) Protective effect of sesamol on the pulmonary inflammatory response and lung injury in endotoxemic rats. Food Chem Toxicol 48:1821-1826.

27. Roman-Blas JA, Jimenez SA (2006) NF-kappaB as a potential therapeutic target in osteoarthritis and rheumatoid arthritis. Osteoarthritis Cartilage 14: 839-848.
28. Xie C, Kang J, Ferguson ME, Nagarajan S, Badger TM, et al. (2011) Blueberries reduce pro-inflammatory cytokine TNF-alpha and IL-6 production in mouse macrophages by inhibiting NF-kappaB activation and the MAPK pathway. Mol Nutr Food Res 55:1587-1591.

29. Shih MF, Chen LY, Tsai PJ, Cherng JY (2012) In vitro and in vivo therapeutics of beta-thujaplicin on LPS-induced inflammation in macrophages and septic shock in mice. Int J Immunopathol Pharmacol 25: 39-48. 